\title{
EFFECTIVENESS OF MONETARY POLICY IN MOROCCO: STABILITY AND IMPLICATIONS
}

\author{
Meryem Erraiteb \\ Center for Economic Research, Shandong University, Jinan, China \\ meryem-erraiteb@hotmail.com
}

\begin{abstract}
The purpose of this study is evaluating the effectiveness of monetary policy in Morocco. The results suggest that the monetary authorities must get out of the narrowness of logic monetarist by adopting a new approach which explicitly privileges the targeting of inflation as the ultimate goal, while referring to a multitude of indicators likely to guide the Central Bank in the conduct of its monetary policy as the exchange rate and interest rate next to the M3 aggregate growth rule. Thus, monetary authorities should out of the narrow sense monetarist by adopting a new approach that focuses explicitly targeting inflation as the ultimate goal, while referring to a multitude of indicators to guide the central bank in the conduct of monetary policy as exchange rate and Interest rate ET and this, alongside the growth rule M3.
\end{abstract}

Keyword: Monetary policy, financial innovations, stability of money demand, inflation targeting

Copyright (c) 2020, International Journal of Economics, Business and Entrepreneurship | IJEBE | FEB-UNILA

\section{INTRODUCTION}

The monetarist theory assigns to the Central Bank the task of maintaining price stability and favors the control of monetary aggregates to achieve this ultimate goal and that, by retaining as a main assumption the stability of the money demand. Inspired by this approach, the Moroccan monetary authorities opted for a policy based on the pursuit of an intermediate target of monetary growth. This mode of action remains, however, subject to a multitude of constraints imposed by the acceleration of the process of reforms and innovations in the monetary and financial market. These structural changes fueling a controversy on the assumption of the stability of money demand, which necessitates an evaluation of the effectiveness of the monetarist approach of the issuing institution. This policy is based on its implementation on a battery of control instruments. The stance of monetary policy depends largely on the institutional environment, it also takes into account the constraints imposed by the economic situation. 
Two main lines marked monetary policy in Morocco, the first orientation based on direct control of the mechanisms that have played an important role in the drying up of liquidity and control inflation. However, they have not missed deficiencies and shortcomings, which motivated their abolition and substituting indirect control mechanisms. This change marked the beginning of a second phase characterized by a new orientation of monetary policy.

Inspired by the teachings of monetarist current, Bank Al-Maghrib has opted for a policy focused on the pursuit of an intermediate target for growth of M3 (which replaced of M1 in 2006). This vision is driven by a speed stability hypothesis of the circulation of money and, in particular, the demand for money. The verification of this last determines the effectiveness of monetary policy in Morocco.

The hypothesis of the stability of money demand is one of the most important assumptions and controversial in economics. Indeed, it was the subject of several studies, most of which focused on savings financially developed. The results these studies have confirmed the stability of the money demand until the mid to from 70 which coincides with the onset of financial innovation and the proliferation of new payment and investment. These two factors are, next to the phenomenon of globalization of capital markets, the factors responsible the apparent instability of money demand standard models 1 .

In the Moroccan case, several empirical studies have focused on the study of stability the demand for money. The results differ between validation and rejection of this stability. One could cite as examples the work of ZEJLY [1990], ARRAU [1991] TAHIRI, and Hoffman [1994] NSOULI. [1995] and ANOUNE and M'KADDEM [1997]. ${ }^{2}$

Forming the basis of the monetarist approach of the authority's currency, the assumption of stability the demand for money may be rebuttable in light of a national context marked by the acceleration of the process of reform and modernization in the monetary and financial market. Given this context, it seems legitimate to ask the following questions: is the money demand function stable in Morocco? And what the implications of a possible instability of this function on the effectiveness of monetary policy Moroccan?

Before evaluating the effectiveness of monetary policy in Morocco, we will expose, as part of the first section of this chapter, the main stages that had to go This policy, while paying particular attention to the strategic and operational framework of the current monetary policy. We will devote the second section to the definition of the money demand function whose stability will be tested later. The results of this test will be used in assessing the effectiveness of monetary policy Moroccan.

\footnotetext{
${ }^{1}$ EL HAFIDI, M., et al., "The stability of the money demand function M3 in Morocco" Law Review and Economics Double Number 21-22, January 2006, p 363.

2 BADDI, H., "The stability of the money demand function in Morocco" Proceedings of the Academic School, Modeling and economic forecasting, Second Session, 2010, June 2011, p 42.
} 


\section{LITERATURE REVIEW}

\section{EVOLUTION OF MONETARY POLICY}

After decades of privileged direct action on bank liquidity, Bank Al-Maghrib conducted during the 90s, to redesign its monetary policy by opting in particular for indirect control tools that, because of their flexibility, allow to best meet the requirements that require changes treasuries banking. The changing context Economic and financial Morocco during the years 2000 pushed the Institute of emission to revise again the strategic and operational framework of monetary policy. These steps will be reviewed as part of this first section.

\section{Monetary policy in Morocco until the early 90}

Monetary policy in Morocco was based until the early 90s on Direct monitoring tools that allowed Bank Al Maghrib to achieve its objective of Monetary growth through direct action on liquidity and bank lending. This range of instruments consisted mainly of management of credit, are mandatory jobs and rediscount technique. Monetary authorities have also adopted the principle of selectivity credits.

\subsection{The credit controls}

The frame of credit is the process by which the Central Bank limits the expansion of bank credit by fixing the maximum rate of expansion during a period determined. This coercive means strict was particularly effective in limiting the growth of the money supply, via direct credit control. Moroccan monetary authorities finally abandoned this instrument in 1991.

\subsection{Required jobs}

By requiring we mean a bank Required number of jobs, the issuing institution sought to limit bank liquidity and so the ability of banks to transform their availability credits. These jobs also allow to Bank Al-Maghrib guide the Concours bank to the Treasury and the priority sectors by the government. Among the major mandatory jobs are:

- The monetary reserve: it is the instrument by which the monetary authorities

- act directly on bank liquidity, forcing banks to deposit in a special account blocked to the issuing bank a given fraction of their deposits. This technique prevents banks to create the currency they desire. If exceeded, the penalties in additional reserve requirements, are generally provided.

- The government paper floor: this is the minimum portfolio that every bank must hold in treasury bills. Bank Al-Maghrib was through this quantitative measure, to direct a portion of bank deposits to finance the budget deficit.

- The portfolio of good CNCA ${ }^{3}$ : this selective measure was intended to promote the financing of agricultural projects. Indeed, banks were brought to devote part of their

${ }^{3}$ Caisse Nationale de Crédit Agricole. 
deposits to purchase vouchers the CNCA contributing to croissant Financial resources for this Specialized Organization.

- The portfolio of discountable medium-term loans (CMTRs) this selective technique allowed the Central Bank to promote the funding of Investment particularly that of SMEs 4 and by forcing banks to devote a portion of their deposits in the distribution of credit to medium-term discountable.

\subsection{The technique of rediscount}

The rediscounting refinancing is a technique that allowed banks to raise their shortterm loans from Bank Al-Maghrib to meet their liquidity needs. The handling of the rediscount ceilings exercised quantity-effect on bank liquidity allowing monetary authorities to control the amount of money created by the banking system. In other words, by increasing or decreasing the rediscount ceiling the issuing institution sought to stimulate or restrict the distribution of credits.

\subsection{The selective credit policy}

To promote the financing of certain strategic sectors of the economy national, monetary authorities have adopted selective credit policy which was based on a variety of measures:

- The non-submission of lending to certain sectors to politics the credit control, particularly loans to cereal crops, medium-term credits re discountable and export credits.

- The rediscount discountable ceiling for medium-term loans, credit, and pre-financing export receivables from export.

- The rediscount at preferential rates, particularly for advances on goods, claims arising on foreign and refinements in $\mathrm{CIH}^{5}$ and CNCA.

- The setting interest rates at relatively low levels for credits for priority sectors.

These administered intervention methods played an undeniable role in limiting the growth pace of money creation. However, they did not lack faults.

Indeed, credit control was a Technical e which undermined the good operation of the Moroccan banking system by limiting the independence of the banks in the conduct of their operations, discouraging innovation, by distorting competition interbank (crystallization market share), hindering thus the growth of the banking activity, and that sanctioning new businesses. besides, certain types of credits, such as those granted to export financing were maintained non-management, which limited the effectiveness of a direct action on bank loans.

\footnotetext{
${ }^{4}$ Small and medium enterprises.

${ }^{5}$ Credit Immobilizer et Hotelier.
} 
For his part, the technique of rediscounting has several drawbacks. All first, this instrument only affected banks that need to refinance, then the rediscount rate was rigid and did not adapt quickly to changing conditions market and finally the Central Bank remained passive concerning banks who had the initiative of refinancing operations.

Moreover, the multiplication of specific measures to promote the financing of certain priority activities has hindered the development of intersectoral competition and putting into question the relevance of the selective credit policy. With the development of capital markets, the use of direct intervention and administered has become ineffective, prompting monetary authorities to opt for indirect control mechanisms.

\section{Monetary policy $90 \mathrm{~s}$}

In 1985, the direct control mechanisms gradually experienced a decline due to three main factors namely, the development of financial intermediation and appropriations for institutions that were not subject to the supervision and mandatory reserves, the significant increase in appropriations not framed and transfer of a significant part of financial intermediation outside the banking system with the creation of new financial instruments such as commercial paper.

These factors combined with the movement of breaking down barriers and deregulation that affected the banking sector, led Bank Al-Maghrib to prefer indirect control tools that, because of their flexibility, best meet the requirements that require changes in bank liquidity.

The main features of the monetary policy at the time were, including the abandonment of direct control mechanisms and the liberalization of interest rates, as well as modernization of methods of intervention of the Central Bank.

\subsection{Abandoning Direct controls and the liberalization of rates interest}

The monetary authorities in January 1991, the removal of quantitative constraints on bank loans. By opting for the dis-frame credit, the government aimed to provide the banking system resources to enable it to contribute more effectively to economic growth, ensuring operators with the funding they need to market.

Similarly, the Institute of emission abolished in January 1988, the rediscount sheet that was reserved for the mobilization of short-term loans. He also performed in June 1995, the elimination of possibilities of automatic recourse and preferred rates conferred rediscounting of export credits and medium-term credits rediscount / SMEs and young entrepreneurs.

Moreover, the liberalization of interest rates, the effective start dates back to 1990, was completed in 1996 with the removal of ceilings on lending rates, and the preferential rates that still benefited certain privileged credits.

\subsection{Modernizing of intervention Bank Al-Maghrib}

From June 1995, the Central Bank changed the terms of refinancing of the banking system by introducing a device comprising four new instruments for indirect regulation of 
monetary aggregates. The instruments on which rested the policy of Bank Al-Maghrib at the time were as follows:

- The 7-day advances on call offers: granted s at the initiative of Bank Al-Maghrib, at a rate which was a floor for interbank rates.

- Advances in 5 days granted at the initiative of the banks, at a rate was a ceiling on the interbank market rate.

- Advances in 24 hours: granted s at the initiative of banks and the Bank Al-Maghrib. the rate applied to this category ahead s was disadvantageous for banks.

- The open market operations: is a technique by which the Bank Central intervenes on the secondary market by buying and selling securities public to act on bank liquidity.

- The monetary reserve: unlike most of mandatory employment, the role of the monetary reserve, for action on bank liquidity was maintained even after the reform.

Finally, note that Bank Al-Maghrib maintained fixing each year of a monetary growth target taking into account the economic outlook and economic forecasts.

These mechanisms have marked a transition from direct monetary policy based on quantitative techniques to indirect monetary policy adapted to the new financial liberalization environment. The adoption of these mechanisms deeply affected the economic and financial landscape of our country and has contributed to its revitalization generating significant gains in economic growth. This was, however, the beginning of a long process of modernization of modes of action Bank Al-Maghrib.

Indeed, it's not until the late 90s with the change of context economic and financial, we have witnessed the establishment of a real political Monetary. These changes have indeed caused a profound change in the conception of political monetary and its implementation.

\section{Monetary policy in Morocco since the reforms of the 2000s}

From the late 90s, Bank Al-Maghrib has started another phase in the modernization of the monetary policy process. During this new stage of reforms, monetary authorities have set themselves the goal adaptation their strategy and instruments to changes in the economy and financial.

\subsection{A strategic framework that makes price stability a priority}

On the monetarist inspiration, the monetary policy strategy of Bank Al-Maghrib based on price stability as a priority objective and multi-criteria approach as diagnostic framework of inflation risk.

The Central Bank bases its diagnosis on inflation risk indicators from the monetary sphere and financial one hand, and representative indicators of the actual second sphere. This multi-criteria approach includes five variables blocks may exercise effects on price stability:

- Evolution of aggregate demand: when inflation is primarily the result of an excess of demand oversupply, the Central Bank conducts the analyses of changes in 
indicators of aggregate demand. This block information and the trend in consumption, investment and net foreign demand;

- Pressures on production capacity: this block is interested in the evolution of s factors Offer making emerge, in particular, tensions on the capabilities of

- production and engendered tensions on the labor market, for businesses, higher demand addressed to them;

- monetary conditions and asset prices: blocklists and monetary variables that influence financial decisions of households and businesses the spending and investment in the short and medium-term. These data related to interest

- rates, the evolution of the money supply, its counterparties and its components, to alternative investments in currency, as well as data from the financial market and real estate;

- Import prices: Morocco, being a small open economy, the level of domestic prices is influenced not only by supply factors and the application internally, but also by changes in import prices. The bank power plant follows for this purpose the development of inflation in the world, international commodity prices, especially the price of oil and the import prices of the different categories of goods;

- The information included in these blocks is synthesized as inflation forecast over a period of six quarters, with the recent evolution of inflation is the last block of the analytical framework base for the making monetary policy decision.

Considering the multi-criteria analysis of the risk of inflation, Bank Al-Maghrib orients its monetary policy in the sense that maintains stability price. Achieving this ultimate objective requires determination an intermediate target as a standard growth of aggregate M3. The monitoring of this monetary standard is through the attachment of an operational target represented by the market rate Interbank. To influence the latter, the Central Bank regulates the conditions of supply and demand for liquidity on the market interbank by implementing a set of instruments and intervention procedures that are the operational framework for monetary policy.

\subsection{An operational framework marked}

The instruments of intervention of Bank Al-Maghrib, as they have been redeveloped during the 2000s, it can be divided into two types of operations, on one hand those from his initiative and the other ones fall the initiative banks. The efficiency of the operational framework of monetary policy is reinforced by the requirement for banks to maintain the availability of accounts with the issuing institution under the monetary reserve.

Re operations raising initiative of Bank Al- Maghrib are the following:

- The 7-day advances on tender, granted in cases of bank liquidity tightening, at a rate equal to the rate of the Central Bank (set at 3\% as of March 2012). Liquidity withdrawals on call offers at the same frequency, used to absorb surpluses and correct any deviations down between the interbank market and its level consistent with the objectives of the Institute of emission. 
- The open market operations: As a reminder, it's interventions to the sale or purchase on the secondary market for Treasury bills. The farm sale ensures sustainable cash withdrawal while the Firm purchase provides power banks in reserve money

- The operations taking or repurchase: it is a private contract between the Institute will issue and a bank, by which both parties agree to give freehold titles at an engagement retrocession, at a price determined in advance.

- The swaps: Those are sales contracts or purchase DH against currency matching respectively clause repurchase or resale at a predetermined exchange rate. These operations are performed for policy needs Monetary through tender or private contract.

Meanwhile, the new statutes of the Central Bank confer the possibility to issue its own debt certificates and exchange on the money market for liquidity control objectives.

Operations under the initiative include banks advances and deposit facilities to 24 hours. These operations are intended to cover the temporary needs of banks in liquidity or guarantee a minimum return on their surplus afternoon. The rates applicable to these standing facilities, less than 100 basis points in rates of major operations times to deposits 24 hours and above 100 basis points at the rate of the main refinancing operations for advances to 24 hours, form the terminals of the corridor indoors which must evolve the interbank rate.

It should be finally noted that Bank Al-Maghrib continues to use the monetary reserve of the technique to increase the needs of banks in central bank money. The innovation introduced in this context is the compensation of sales made under this reserve rate of $0.75 \%$.

In this first section, we highlighted the main stages that had to pass monetary policy in Morocco. special attention was paid to the current monetary policy, focusing particularly on its objectives, framework strategic, and implementation mechanisms at the operational level. But is it an effective policy? It's that we will try to check through the next section.

\section{RESULTS AND DISCUSSION}

\section{THE EFFECTIVENESS OF THE POLICY IN BANK AL MAGHRIB}

The Moroccan authorities adopt a monetary policy based on the precepts monetarists and giving change, specifically M3, its intermediate target of choice. However, we can no longer recognize the monetary aggregates still play this role given the major changes that known to finance and the economy in the various countries of the world. What we beg the question of whether this policy remains effective in Morocco. This section tries to make a respond to this question through an analysis that combines theoretical and empirical dimensions.

\section{The theoretical basis of a policy based on monetary aggregates}

To create favorable conditions for the effective functioning of the economy, monetarists have enacted several of precepts that those responsible for monetary policy 
should respect and implement. Indeed, they assigned to the Central Bank a unique mission namely, the maintenance of price stability defined by a low target at constant inflation. This stability is provided by adherence to a policy rule anchored to control the quantity of money. The final aim is maintaining confidence in the currency due to the enhanced credibility of the Central Bank. For monetarists, the conduct of monetary policy must be based on a magnitude that manifests both stability and control power by monetary authorities 6 . They base their reasoning on the assumption of exogenous supply of currency and the stability of real-term money demand. they preferred to adopt the money supply as the target variable or intermediate target.

Indeed, the monetarist's money demand is stable. This presupposes the stability of its circulation rate (quantitative theory of money). Both assumptions are the subject of many disputes 7 .

In Morocco, and since the 90s, the conduct of monetary policy has become increasingly difficult because of the disruption of the content of the monetary aggregates that constitute its milestones par excellence. This disturbance is due mainly to the emergence of financial innovations that have made the border between monetary financial assets and rather blurry, Hence the multitude of quality assets with currency change and evolve over time. These constraints do not favor a priori, the stability of the money demand function.

Also, the money circulation rate is increasingly unstable. This is can be seen from the graphs below. The currency rate of circulation is shown by the ratio of the gross domestic product and M3 (GDPM 3). AT Note that the changing velocity of the currency is part of a downward trend. This means that the evolution of the Money supply in the market is more important than growth in real activity.

\footnotetext{
${ }^{6}$ RUFFINI Pierre Bruno., The monetary theories, Dunod 1993, p 230.

${ }^{7}$ BEZIADE Monique., money Masson, Paris, 1986, p 410.
} 
Key indicators of monetary statisties

\begin{tabular}{|c|c|c|c|c|c|}
\hline & \multirow{2}{*}{$\begin{array}{c}\text { Owasuandiny amasum } \\
\text { Decomber-19 }\end{array}$} & \multicolumn{2}{|c|}{$\Delta$} & \multicolumn{2}{|c|}{$\Delta(*)$} \\
\hline & & Nowemiber-19 & December-18 & Nowniber-19 & Decenber-18 \\
\hline Mi & 911855 & 31083 & 53158 & 3,54 & $6,2 \mathbf{A}$ \\
\hline M2 & 1078310 & 31900 & 60423 & $3,0 \mathrm{~A}$ & $5,9 \mathbf{A}$ \\
\hline M3 & $13707 \mathrm{SB}$ & 26 4as & so 134 & $2,0 \mathrm{~A}$ & $3, \mathrm{n} \mathbf{A}$ \\
\hline Liquid investment aggregate & 746982 & 8046 & 46878 & $1,1 \mathrm{~A}$ & $6,7 \mathbf{A}$ \\
\hline Curreacy in circulation & 250875 & 65 & 17273 & 0,34 & $7,4 \mathrm{~A}$ \\
\hline Banking deponits included from broad mose $y^{(1)}$ & 947175 & 19292 & 24209 & $2,1 \mathbf{A}$ & $2,6 \mathbf{A}$ \\
\hline Dermand deposits with the banking system & 586573 & 22029 & 25845 & $3,9 \mathrm{~A}$ & $4,6 \mathrm{~A}$ \\
\hline Time accounts and fixed-term bills & 149145 & -3748 & -11961 & $-2.5 \mathrm{~V}$ & $-7,4 \mathbf{V}$ \\
\hline Securities of money market UCTIS & 55497 & 934 & -1611 & $1,7 \mathbf{A}$ & $-1,8 \mathbf{v}$ \\
\hline Net international reserves & 245622 & $6 \operatorname{es} 2$ & 14957 & $2,5 \mathrm{~A}$ & $6,5 \mathrm{~A}$ \\
\hline Net chaims on central governument & 21492 & 9091 & 1193 & $4,4 \mathbf{A}$ & $5,9 \mathbf{A}$ \\
\hline Lending to the economy & 1078668 & 20495 & 55776 & $1,9 \mathrm{~A}$ & $5,5 \mathbf{A}$ \\
\hline Louns of other depositary cerporations ${ }^{\text {(a) }}$ & 123359 & 25103 & A) 361 & $2,8 \mathrm{~A}$ & $5,4 \mathbf{A}$ \\
\hline Bank loans & 916667 & 24610 & 46051 & $2,8 \mathrm{~A}$ & $5,3 \mathbf{A}$ \\
\hline \multicolumn{6}{|l|}{ By economic purpose } \\
\hline Real estate loans & 276742 & 909 & 9443 & $0,3 \mathbf{A}$ & $3.5 \mathrm{~A}$ \\
\hline Hoesing loans & 214772 & -45 & 7687 & 0,0 . & $3,7 \mathbf{A}$ \\
\hline Of which: purticipation financing of housing & 7796 & 410 & 3712 & $5,6 \mathrm{~A}$ & $90,9 \Delta$ \\
\hline Loans to property developers & 59561 & 2702 & 1569 & $4,8 \mathrm{~A}$ & $2,7 \mathbf{A}$ \\
\hline Deber accounts and owerdraft facilities & 190311 & 4712 & 12587 & $2,5 \mathrm{~A}$ & $7,1 \mathrm{~A}$ \\
\hline Equipment loans & 183177 & 3352 & 9148 & $1,9 \mathrm{~A}$ & 5,34 \\
\hline Consimer loans & 56522 & 45 & 2445 & $0,1 \mathbf{A}$ & $4.5 \mathrm{~A}$ \\
\hline Mineellaneous claims & 140744 & 16319 & 8485 & $13,1 \wedge$ & $6,4 \mathrm{~A}$ \\
\hline Non-performing loans & 69170 & -727 & 3943 & $-1,0 \mathbf{\nabla}$ & $6,0 \boldsymbol{\Lambda}$ \\
\hline \multicolumn{6}{|l|}{ By institutional sectors } \\
\hline Other financial corporations & 132432 & 16546 & 6356 & $14,3 \mathrm{~A}$ & $5,0 \mathrm{~A}$ \\
\hline nos-financial sector & 784235 & 8064 & 39695 & $1,0 \mathrm{~A}$ & $5,3 \mathbf{A}$ \\
\hline Public weter & 72710 & 2625 & 1781 & $3,7 \mathrm{~A}$ & $2,5 \mathbf{A}$ \\
\hline Local government & 22381 & 1476 & 2857 & $7,1 \mathbf{A}$ & $14,6 \mathrm{~A}$ \\
\hline Public nonfinancial corporations & 50329 & 1149 & -1075 & $2,3 \mathbf{A}$ & $-2,1 \mathrm{~V}$ \\
\hline Private sector & 711524 & 5440 & 37913 & $0,8 \mathrm{~A}$ & $5,6 \wedge$ \\
\hline Other nonfinancial corporations & 367325 & 5978 & 24471 & $1,7 \boldsymbol{\Lambda}$ & $7,1 \boldsymbol{\Lambda}$ \\
\hline Households and NFISH ${ }^{(3)}$ & 344199 & -538 & 13443 & $-0,2 \mathbf{\nabla}$ & $4,1 \mathrm{~A}$ \\
\hline
\end{tabular}

Source: Calculated from data BAM $^{8}$

Therefore, the monetarist approach risk now of being unsatisfactory and inoperative for monetary policy, since the evolution of monetary aggregates is unstable, and other indicators are possibly be considered.

To test the consistency of monetary aggregates as intermediate to objective Moroccan monetary policy and thus evaluate the effectiveness of the latter, we go through econometric analysis testing the stability of the money demand function in Morocco and, having just defined it.

\section{Definition of money demand function in Morocco and study of its stability}

Moroccan monetary authorities distinguish between three monetary aggregates M1, called money supply consisting of currency and scriptural; M2 consists of M1 plus sight deposits (savings accounts at banks) and M3 money supply called, consists of M2 and other monetary assets (including deposit accounts, savings bonds, certificates of deposit with residual maturity up to 2 years and titles UCITS $^{9}$ monetary).

\footnotetext{
${ }^{8}$ Bank Al-Maghrib.

${ }^{9}$ Collective Investment in Transferable Securities.
} 
Comp kept you in the innovation process and financial deregulation began in the 90s, the Moroccan monetary authorities were brought in January 2006 to adopt a new nomenclature for classifying the monetary aggregates. And since it is M3 which is the objective through monetary policy by replacing M1. This will, therefore, urge to remember M3 in defining our demand function currency, which we will study the stability thereafter.

Theoretically, it was proven by different approaches (Keynesian, monetarist ...) that the function of money demand usually depends on a small number of factors, namely, $\mathrm{GDP}^{10}$ and real interest rates ${ }^{11}$. In the light of these approaches and adding inflation as a third explanatory variable, we define the relation real money demand function as follows:

M3 /CPI $=f y, r, i$

with:

y : Real GDP.

r $\quad$ : rate interest Interbank.

I : rate inflation.

CPI : Consumer price index.

M3 /CPI: Request for real money.

Economic theory does not specify the exact functional form to be taken equation money demand. However, the most common form in empirical work is the log-linear form.

Therefore, our equation becomes:

$\operatorname{In}(\mathrm{M} 3 / \mathrm{CPI})=\mathrm{A}+\mathrm{B} \operatorname{In}(\mathrm{y})+\mathrm{C} \operatorname{In}(\mathrm{r})+\mathrm{D} \operatorname{In}(\mathrm{i})+\mathrm{i}$

i Terme error.

This model is a regression model which explanatory variables: gross domestic product used as an indicator of economic activity, the interest rate on the interbank market and the inflation rate calculated from the index price consumer base year being $2018^{12}$. Inflation $\mathrm{i}$ is calculated in principle based on the following formula:

$\mathrm{i}=\frac{\mathrm{CPIn}-\mathrm{CPIn}-1}{\mathrm{CPI}-1} \times 100$

with:

CPI $\mathrm{n}$ : Price Index Consumer of the Year $\mathrm{n}$.

CPI n-1 : Price Index Consumer of the Year n-1.

\footnotetext{
${ }^{10}$ Gross domestic product.
}

${ }^{11}$ EL HAFIDI, M., "The demand for money M1 and M2 in Morocco study in terms of the co-integration" Law Review and Economics Double Number 21-22, January 2006, p 347.

${ }^{12}$ Note: for the period before 2018, the series of the consumer price index (CPI) is made based on the rate of change of the cost index of the life (ICV) (connection). 
However, since our model is established in log form, and to avoid negative signs do occur, they will be limited to the rate calculation 'inflation the following ratio:

$\operatorname{In}(\mathrm{i})=\operatorname{In}\left(\frac{\operatorname{CPI} n}{\operatorname{CPI} n-1}\right) \times 100$

The estimated regression coefficients will be determined by the method of the ordinary least squares (OLS) over a period that ranges between 1998 and 2018. The effectiveness of this method assumes the nullity of the expected errors and the normality of their distribution, the absence of autocorrelation of errors and lack of heteroscedasticity.

\section{Implications instability the demand for money the effectiveness of Monetary policy in Morocco}

According to the results of our empirical study, we can conclude that the strategy adopted by Bank Al-Maghrib to master the Inflation and which focuses on targeting the growth of M3, is not p read effectively. Indeed, the theoretical use of monetary aggregates as a single intermediate target of monetary policy is the assumption monetary stability of the money demand function, this gold assumption is not verified in Morocco.

The lack of a perfect relationship between inflation and the evolution of Money supply has 13 Morocco, confirms the findings of this study. Indeed, in a context of open markets marked by financial innovations continuously, inflation longer depends exclusively on the growth of the money supply but also changes in prices internationally (imported inflation) the changes in aggregate demand pressures on production capacity, etc.

Inflation and growth of M3

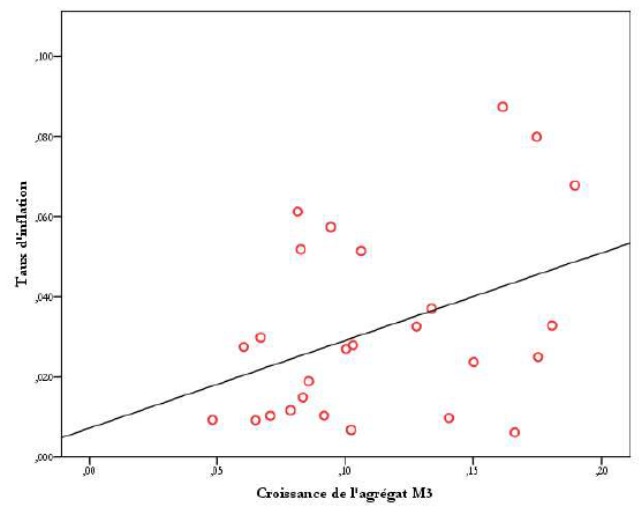

Source: Calculated from BAM and HCP 14

\footnotetext{
13 This goes against the thinking of Milton Friedman which states that "inflation is always and everywhere a monetary phenomenon. "

14 High Commission for Planning.
} 
It would be wiser to seek new targets that could better conduct monetary policy. The latest studies in this direction, proposing the central bank to target the final variable directly namely, inflation. This is called the targeting the inflation. This strategy is to determine an inflation target as a definite point or range of points. The central bank then proceeds to the estimation of future inflation, any deviation from this forecast level compared to the target should result in corrective action by the monetary authorities. Another essential characteristic of inflation targeting policies is their degree of high transparency. Indeed, the Central Bank undertakes, in this context, to clearly communicate its guidance, and argue his decisions. In parallel, it is more appropriate not to definitively rule money growth rule, alongside other indicators used by the central bank, which could be used as a landmark to guide the issuing institution in conducting its monetary policy to avoid complacency monetary.

Retained by Kaldor, in the 60s, as a pole of his magic square, the Inflation control is necessary since it allows economic agents to anchor their expectations and make them consumption decisions, savings and investment without affecting their profitability.

The strategy of Morocco's Central Bank is part of an approach monetary based on monetary targeting under the assumption the stability of money demand and stability the evolution of its speed of movement. Now, these two hypotheses are not verified in the case of Morocco since the demand for money and money circulation rate became unstable under the effect of speeding up the process reforms and financial innovations. This question the relevance of using M3 as single intermediate target of monetary policy in Morocco and thus limits its effectiveness.

Thus, monetary authorities should out of the narrow sense monetarist by adopting a new approach that focuses explicitly targeting inflation as the ultimate goal, while referring to a multitude of indicators to guide the central bank in the conduct of monetary policy as exchange rate and Interest rate ET and this, alongside the growth rule M3.

Nevertheless, the use of a set of indicators must be done with caution as it is may induce the central bank in error. Indeed, these Indicators can generate conflicting signals. besides, the observation of a series of indicators simultaneously could destabilize the monetary policy by pushing the Central Bank to frequently change its direction. Under these conditions, it is necessary to deepen the reflection to find an optimal combination of the weight of the monetary aggregate and that of other indicators to integrate a man intelligent in the process of decision making of the monetary authorities.

\section{CONCLUSION}

Selected by Kaldor in the 1960s as a pole in his magic square, the Inflation control is necessary insofar as it allows agents economic to anchor their expectations and make their consumption decisions, savings and investment without affecting their economic profitability.

The strategy of the Central Bank of Morocco is part of an approach monetarist based on monetary targeting under the assumption of stable demand and the stability of the evolution of its circulation speed. Now, these two hypotheses are no longer verified in the Moroccan case since the demand for money and the speed of currency circulation became 
unstable due to the acceleration of the process financial reforms and innovations. This calls into question the relevance of the use of the M3 aggregate as the sole intermediate objective of monetary policy in Morocco and thus limits its effectiveness.

Therefore, the monetary authorities must get out of the narrowness of logic monetarist by adopting a new approach which explicitly privileges the targeting of inflation as the ultimate goal, while referring to a multitude of indicators likely to guide the Central Bank in the conduct of its monetary policy as the exchange rate and interest rate next to the M3 aggregate growth rule.

However, the use of a set of indicators should be done with caution in to the extent that it is likely to mislead the Central Bank. Indeed, these indicators can give contradictory signals. In addition, the observation of a series of indicators simultaneously risks destabilizing monetary policy by pushing the Central bank to change its guidelines frequently. Under these conditions, it turns out necessary to deepen the reflection to find an optimal combination between the weight of the monetary aggregate and that of the other indicators in order to integrate them in a way intelligent in the decision-making process of monetary authorities.

\section{REFERENCES}

Florin AFTALION and Patrice PONCET, Monetarism, Edition Que Sais-je?, Presses Universitaires de France, 1995.

Mohamed Azzedine BERRADA, The new capital markets in Morocco, SECEA editions, 1998.

Monique BEZIADE, Currency, Masson, Paris, 1986.

Régis BOURBONNAIS, Econometrics, DUNOD, Paris, 2002

Michelle DE MOURGUES, Financial system and monetary theory, Economica, 1988.

Christian BORDES, Monetary policy, La Découverte, Paris, 2007, pp 16 - 19.

Sophie BRANA and Michel CAZALS, La Monnaie, Dunod, Paris, 2006.

Pierre-Bruno RUFFINI, The monetary theories, Dunod, 1993.

Hicham BADDI, "The stability of the money demand function in Morocco", Acts of the Academic School, Modeling and economic forecasting, Second session 2010, June 2011, pp $39-62$.

Mr. EL HAFIDI, Mr. AIT OUDRA and Mr. BENALI, "The demand for money M1 and M2 in Morocco: study in terms of cointegration ", Law and Economy Review, Double issue 21-22, January 2006, p 347.

Mr. EL HAFIDI, Mr. AIT OUDRA and Mr. BENALI, "The stability of the function of request for M3 money in Morocco ", Law and Economics Journal, Double issue 21-22, January 2006, p 363.

Abdellatif EL M'KADDEM and Habib ANOUNE, "Financial innovations, request and monetary policy in Morocco ", Journal of the Association of Moroccan economists, $n{ }^{\circ} 21$, Autumn 1997, pp 5-20.

Jean-Paul POLLIN, "Theory of monetary policy: Sketches of a refoundation ", Economic review, Presses de Sciences Po, n 3, 2005, pp 507 - 539.

Institutional publications: Bank Al-Maghrib, Annual reports, Rabat, 1990 to 2011.

Bank Al-Maghrib, Monetary Policy Report $N^{\circ} 01 / 2006$, Document prepared for the Board of Bank Al-Maghrib, Rabat, December 2006. 